\title{
La Biblia al servicio de la espiritualidad de la infancia
}

José Andrés Sánchez Abarrio'

\section{Resumen}

Los niños poseen una capacidad innata para lo espiritual. Sin embargo, ciertos prejuicios de los adultos, unido al desconocimiento de los particulares ámbitos donde se desarrolla la espiritualidad en la infancia, hacen que se preste poca atención a esta dimensión común a todos los niños. La identificación de esos espacios y ámbitos privilegiados posibilita a los que nos dedicamos a la formación de los niños situarnos como facilitadores de la experiencia espiritual. En nuestra tarea de servicio a la espiritualidad infantil, podemos ofrecer a los niños los relatos bíblicos, como adecuados instrumentos para expresar sus experiencias.

\section{Palabras claves:}

Espiritualidad infantil, Biblia, narraciones bíblicas, Godly Play

1 Doctor en Teología bíblica. Director del Área de Ciencias de la Religión de La Salle Campus Madrid. Profesor de Sagrada Escritura en el Instituto de Ciencias Religiosas y Catequéticas San Pío X. 
La atención a la espiritualidad de la infancia ha cobrado un notable incremento en los últimos años del siglo pasado y en los primeros del presente, especialmente en el mundo anglosajón ${ }^{2}$. En el ámbito de la educación de la fe nos hemos acercado a la espiritualidad de la mano de lo religioso, en un proceso que muchas veces va de lo externo a lo interno. Guiados por ciertas visiones racionalizadas de lo espiritual, muchos pensaban que los niños no podían tener experiencias espirituales porque todavía no habían alcanzado la capacidad de razonamiento formal, lo cual ocurre generalmente en la adolescencia. Desde tal concepción se buscaba dotar a los niños de ideas, mandamientos, dogmas y principios que le permitieran construir una sólida espiritualidad, pasando por alto hecho de que la vida espiritual de los niños se desarrolla, por el contrario, desde el interior hacia el exterior. Cuando hablamos de espiritualidad infantil lo primero no es el lenguaje verbal, ni saber dar explicaciones de lo que vive o siente el niño sino su manera de estar con Dios y Dios con él ${ }^{3}$.

La conciencia de que los niños viven experiencias espirituales, que muchas veces pasan inadvertidas para los adultos, se ha hecho más evidente a medida que nos percatamos de que poseen una capacidad espiritual innata. En efecto, la espiritualidad es algo natural que forma parte de la infancia y no es una capacidad de algunos niños precoces o "especiales". La investigadora Rebecca Nye sostiene que la conciencia espiritual de los niños tiene un carácter relacional: surge o pone su atención en las relaciones profundamente arraigadas entre ellos y las personas, el mundo, su yo interior y Dios. Es lo que ella llama "conciencia relacional" . Aunque a veces los adultos

2 El número de publicaciones sobre el particular es ingente. Desde 1998 se edita periódicamente la revista inglesa International Journal of Children's Spirituality que constituye un importante punto de encuentro entre investigadores, teólogos, psicólogos, pastoralistas, educadores y padres. Cf. https://www.tandfonline.com/toc/cijc20/current. Para una síntesis de los estudios sobre espiritualidad de la infancia, ver J. Mata-Mac-Mahon, "Reviewing the research in children's spirituality (2005-2015): proposing a pluricultural approach", International Journal of Children's Spirituality 21/2 (2016) 140-152.

3 R. Nye, La espiritualidad infantil. En qué consiste y cómo enriquecerla, Madrid 2019, 20.

4 D. Hay - R. Nye, The Spirit of the Child, London 2006, 109. 
solemos tener tendencias bastante individualistas o incluso narcisistas al referirnos a nuestra espiritualidad, durante la infancia, la espiritualidad tiende a buscar el "estar en relación", responder a una llamada de relacionarse con algo más que "uno mismo", es decir, con otros, con Dios, con la creación o con un sentido interior del propio ser más profundo ${ }^{5}$. Este encuentro con la trascendencia puede producirse con determinadas experiencias, en diferentes momentos y a través de actividades imaginativas o reflexivas.

Identificar los ámbitos que propician la experiencia espiritual en la infancia será el primer paso. En todos ellos, los adultos podemos hacernos presentes e interactuar con los niños. En nuestra tradición religiosa, encontramos en las narraciones bíblicas un excelente recurso para acompañar a los niños en la búsqueda de la presencia divina.

\section{1. Ámbitos de desarrollo de la espiritualidad de la infancia}

Así como no existe un consenso unánime a la hora de encontrar una definición global de espiritualidad, tampoco lo existe para determinar en qué ámbitos o circunstancias se puede detectar y desarrollar la espiritualidad infantil. Una vez más, nos encontramos con que lo espiritual escapa a nuestras pretensiones de programación. Sin embargo, en el campo educativo y pastoral resulta de suma importancia detectar esos "lugares espirituales", aquellas fuentes que pueden nutrir la dimensión relacional del niño y, por tanto, su espiritualidad.

La investigadora Rebecca Nye ha desarrollado un modelo basado en “criterios clave para elaborar una política de 'prácticas idóneas' de espiritualidad cuando se trabaja con niños" ${ }^{6}$. En el fondo, se trata de cinco ámbitos donde el niño puede desarrollar su espiritualidad y que los adultos deberíamos cuidar especialmente. Los presenta en modo de acróstico, SPIRIT, para poder recordarlos con más facilidad, si bien todos son igual de importantes:

"Espacio (Space). El entorno tiene influencias positivas y negativas en el bienestar espiritual. Sin duda, el espacio físico que nos rodea es im-

5 Nye, La espiritualidad, 20-21.

6 Nye, La espiritualidad, 67-87. 
portante. Hay lugares que parece que nos hacen sentir que Dios está allí. Sin embargo, si pensamos en los niños, los lugares que a ellos les evoque la presencia de Dios no tienen por qué ser los mismos que empleamos los adultos. Cuando hablamos de espacios, la autora también se refiere al espacio emocional, aquel que les permite apartarse, pensar sus propios pensamientos y expresar sus opiniones, aquel espacio que les ofrece seguridad y cuidado. No olvidemos que también el espacio auditivo es importante: cuando estamos con niños debemos hablar menos y escuchar más, dejando espacios que les permitan reflexionar, interiorizar lo que se ha dicho, pero también escuchar lo que está pasando en su propio interior.

Proceso (Process). Algo que nos recuerdan todos los maestros y caminos espirituales es que la espiritualidad tiene que ver con el proceso más que con el producto. Cuando ponemos el acento en el producto la espiritualidad se vuelve "materialidad", deja de ser lo que está llamada a ser. Cuando trabajamos con niños esto lo percibimos, pero tendemos a marcar ese camino con productos, logros, que se pueden considerar hitos u "objetivos de aprendizaje". Los niños necesitan percibir que lo importante es el proceso y no el producto.

Imaginación (Imagination). No es una palabra que se suela encontrar en un manual de espiritualidad. Podríamos decir que hay un cierto temor al empleo de la imaginación en el ámbito religioso y espiritual y, seguramente, porque pensamos que nos movemos en el terreno de las grandes formulaciones y dogmas. Sin embargo, la imaginación es una habilidad espiritual que nos invita a abrirnos y ser creativos, a imaginar nuevas posibilidades y crear nuevos significados.

Relación (Relationship). La espiritualidad es tan privada -entre Dios y el niño-, como colectiva -relaciones y conexiones-. Es más, algunos piensan que el espacio entre los individuos es la "tierra sagrada", el verdadero espacio donde acontece lo espiritual. Por eso, la calidad de nuestras relaciones puede sentar las bases de cómo nos relacionamos espiritualmente. Cuando hablamos de desarrollo espiritual es importante valorar el intercambio, el respeto, la escucha y la participación abierta y honesta. No tiene que ver con "respuestas correctas" o premiar las aportaciones.

Intimidad (Intimacy). La relación necesita también de un espacio íntimo, un "guardar distancia". La espiritualidad se nutre de la intimidad y aprovecha cada oportunidad para acercarse, profundizar, arriesgarse y dedicar tiempo a lo importante. En el trabajo con los niños tendremos que procurar crear espacios de intimidad, donde "sentirse segu- 
ros", donde se respete su ritmo interior y no se vean acosados por el ritmo emocional de marcan los estímulos externos.

Confianza (Trust). Puesto que la espiritualidad escapa a toda cuantificación, la confianza resulta esencial para el mantenimiento de la vida espiritual. Se requiere la confianza para abrirnos a diferentes formas de conocer y de no conocer, para acceder a un mundo que no se hace evidente a nuestros ojos. No es suficiente decir que aquí "hay confianza". La confianza se integra en nuestras actitudes y acciones y los niños la perciben de una manera especial. En las relaciones educativas socavamos la confianza cuando adoptamos un papel demasiado autoritario o controlador, no confiamos en los sentimientos de los niños o en la acción callada y misteriosa de Dios".

Otro investigador, Tobin Hart, que ha dedicado años de estudios y miles de horas entrevistando a niños y adultos a cerca de sus experiencias espirituales, ha identificado a su vez cinco estilos o cauces naturales por los que suele discurrir la espiritualidad infantil y que a continuación resumo con sus palabras:

"La sabiduría. Entendida no como un objeto o algo que pueda acumularse, sino una actividad, un modo de ser y conocer que sólo llega cuando la mente y el corazón están abiertos. La sabiduría no sólo nos permite ver en lo más profundo de las cosas, sino ubicarlas en su adecuada perspectiva. La fuente interior de la sabiduría ha recibido diversos nombres: "maestro interior" (Sri Aurobindo), "hombre interior" (maestro Eckhart) o "superalma” (R. W. Emerson). La búsqueda de la sabiduría no tiene tanto que ver con lo que sabemos, como con el modo en que lo sabemos. Desde que en el siglo XII san Buenaventura distinguiera los "tres ojos del conocimiento" -el ojo de los sentidos, el ojo de razón y el ojo de la contemplación-, sabemos que la mente contemplativa constituye una modalidad de conocimiento directo y no racional que complementa al conocimiento analítico. Nuestra mentalidad racionalista ha empañado el ojo de la contemplación con la nube de la desconfianza. Sin embargo, en la mayoría de los niños, la visión directa de la contemplación sigue tan viva como siempre puesto que los niños son contemplativos por naturaleza.

El asombro. Con el término "asombro" nos referimos a una constelación de experiencias que comprenden desde el temor reverencial, la conexión, el gozo y la intuición, hasta un profundo sentimiento de

7 T. Hart, El mundo espiritual secreto de los niños, Barcelona 2006. 
amor y fascinación que es capaz de provocar en niños (y adultos) una apertura tan vasta y profunda que puede desembocar en el éxtasis y el estado unitivo. En esos momentos se puede sentir a la divinidad y reconocer el modo en que se comunica con nosotros. El asombro nos ayuda a percibir la naturaleza sagrada del mundo. Aunque el mecanicismo, el materialismo y la modernidad pretenden "desacralizar" el mundo reduciéndolo a un puñado de materia inerte y manipulable, el asombro hace que lo sagrado no se aleje nunca de nuestro campo visual y que podamos reconocer su presencia en nuestro entorno. No sólo poseemos una capacidad innata para el asombro, sino que es una necesidad pero, por distintos motivos relacionados con el miedo y el ansia de control, nuestra sociedad tiende a malinterpretar y, en consecuencia, a reprimir dicha capacidad de asombro incluso en los niños. Al igual que muchos místicos y grandes sabios, los niños experimentan de modo natural experiencias más o menos profundas de asombro que, en ocasiones, les llevan a penetrar en el gran misterio que les rodea y que les dejan un profundo sentimiento de reverencia por la vida y también la necesidad de plasmar y dar sentido a lo que ven. Los niños nos recuerdan que vivimos inmersos en un vasto océano de maravilla y misterio.

Entre el tú el yo. La perspectiva relacional de la espiritualidad afirma que ésta se experimenta en la intersección de nuestras vidas o, tal como lo denomina Martin Buber, en el "entre": "El espíritu no reside en el yo, sino entre el tú y el yo. No es como la sangre que circula en nuestro interior sino, más bien, como el aire que respiramos". Cuando abrimos nuestro corazón para conocer realmente a los demás, podemos percibirlos de un modo mucho más profundo y el amor y la compasión aparecen de manera natural. La espiritualidad relacional significa comunión, conexión, comunidad y compasión y se basa en el modo en que concebimos el mundo y nos relacionamos con él.

El cuestionamiento. Ya se trate en niños pequeños o de científicos formados, el cuestionamiento no trata tan sólo de encontrar respuestas. La profundidad está más relacionada con la formulación de buenas preguntas que con el hecho de tener todas las respuestas. El cuestionamiento de nuestras creencias -ya se refieran a la iglesia o al universo de las hormigas- puede ser algo más que un mero ejercicio intelectual y servir de práctica espiritual que nos ayude a liberar nuestra mente para ver de un modo más claro y directo. La rigidez es ajena a la práctica espiritual, y las preguntas de los niños pueden ayudar a romper su maldición. Las preguntas de los niños nos permiten comprender que damos por sentadas muchas cosas como si fuesen hechos irrefutables. 
En consecuencia, cuando les prestamos la debida atención, sus preguntas pueden poner al descubierto nuestras asunciones y ayudarnos a reconsiderar nuestra comprensión de las cosas.

Ver lo invisible. La práctica totalidad de las tradiciones espirituales reconocen la existencia de planos invisibles que coexisten con el nuestro. La ciencia moderna afirma que hay que ver para creer, es decir, que sólo debemos creer en las cosas que vemos directamente. Para la mayoría de la gente ese credo es bastante aceptable puesto que les proporciona algún tipo de certeza que les ayuda a evitar la superstición y la locura. Sin embargo, en lo que respecta a las cuestiones espirituales, muchas veces es necesario creer para ver. Más concretamente, eso significa que, para abrirnos a lo que es anterior a nosotros, debemos dejar en suspenso nuestra incredulidad. Eso no quiere decir que tengamos que renunciar a nuestra capacidad crítica o convertirnos en ciegos seguidores de alguna idea o doctrina, sino tan sólo que tenemos que desactivar provisionalmente nuestro juicio crítico para abrirnos a otras posibilidades. Ése es el sentido de fe. La fe erige puentes entre lo conocido y lo desconocido, abre nuestra conciencia a nuevas posibilidades y nos permite vislumbrar lo invisible. Los niños tienen más fácil acceso que otros a esas dimensiones; y todos poseen, de un modo u otro, la capacidad de ver más allá de las apariencias".

Tanto los criterios de Rebecca Nye como los cauces que señala Tobin Hart - con muchos elementos en común- nos ofrecen unas pistas muy valiosas sobre las que seguir los pasos del desarrollo espiritual de los niños. ¿Qué atención estamos prestando a estos ámbitos en la práctica educativa o catequética con los niños? ¿Podemos cambiar algunas de nuestras actitudes docentes, implementar nuevos procedimientos o reorientar ciertas prácticas en favor de un mayor respeto hacia la dimensión espiritual de los niños? Entre los muchos medios posibles, vamos a presentar a continuación el empleo de la Biblia, y especialmente de las narraciones, como un instrumento privilegiado para el desarrollo de la espiritualidad del niño en la educación o en la catequesis.

\section{Las narrativas bíblicas: una manera de nutrir la espiri- tualidad de la infancia}

El movimiento de descubrimiento y estudio de la espiritualidad del niño se está viendo acompañado por una creciente atención 
a su figura en la Biblia y en el mundo antiguo ${ }^{8}$. Tal es así, que la mayor asociación bíblica, la americana Society of Biblical Literature, cuenta desde 2008 en sus reuniones anuales con una sección exclusiva dedicada a este campo de estudio: "Children in the Bible World”. Los estudios bíblicos están ayudándonos a rescatar la voz silenciada y las experiencias particulares de los niños, así como a comprender su concepción y lugar en las sociedades antiguas 9 .

Sin embargo, no vamos a ocuparnos aquí de los resultados que esta atención a la "lectura infantil" de la Biblia está aportando. Más bien pretendemos poner la Biblia en las manos del lector, en este caso, del lector infantil. Desde hace varias décadas, los teóricos de la literatura están poniendo en valor la importancia del lector en el proceso de lectura y comprensión de un texto, especialmente narrativo ${ }^{10}$. Todo texto literario requiere de un lector que se sumerja en los espacios en blanco que el autor ha dejado entre las palabras escritas. A. M. Trousdale recoge una tradición rabínica según la cual Dios escribió la Torá en letras de fuego negro sobre el fuego blanco del pergamino; el fuego blanco se encuentra en los espacios entre y alrededor del negro. El fuego negro está fijo para siempre; pero el fuego blanco se enciende en cada tiempo y lugar. El fuego negro establece el objeto canonizado que todos podemos ver ante nosotros; los espacios en blanco representan el potencial infinito para la interpretación actual del texto ${ }^{11}$. Es decir, cualquier texto literario y,

8 Para una síntesis sobre el nacimiento, desarrollo y tendencias en los estudios bíblicos relativos a la infancia, con abundante bibliografía, ver S. W. Flynn, "Children in the Hebrew Bible: A field in growth", Religion Compass 12 (2018) 1-11 y J. F. Parker, "Children in the Hebrew Bible and Childist Interpretation", Currents in Biblical Research 17 (2019) 130-157.

9 Algunas de las últimas monografias más recomendadas: M. J. Bunge - T. E. Fretheim - B. R. Gaventa, The Child in the Bible, Eerdamns, Grand Rapids 2008; S. Betsworth - J. F. Parker, T\&T Clark Handbook of Children in the Bible and the Biblical World, London 2019; K. H. Garroway - J. W. Martens, Children and Methods: Listening To and Learning From Children in the Biblical World, Brill, Leiden 2020.

10 A. M. Trousdale, "The Role of Literature in Children's Spiritual Development", en M. de Souza et al (eds.), International Handbook of the Religious, Moral and Spiritual Dimensions in Education, Springer, Dordrecht 2009, 1125-1135.

11 A. M. Trousdale, "Black and white fire: the interplay of stories, imagination and 
cómo no, también la Biblia, requiere que el lector tome parte en el proceso de lectura. Esto que aprendemos de la teoría literaria encaja perfectamente con la lectura creyente que hacemos de la Biblia: no leemos la Biblia para saber más del pasado, ni siquiera para admirar o imitar las gestas de nuestros antepasados -aunque todo eso sea interesante- sino que la leemos para encontrarnos con Dios. Los espacios en blanco son los que posibilitan el encuentro con Dios, pues Dios no está en el fuego negro de la letra, cosificada y fijada. Cuando el lector/oyente logra entrar en esos espacios, entra en la relación con Dios. En el origen y en el final de la Biblia hay "relación". Por eso resulta un medio privilegiado para desarrollar y nutrir nuestra "conciencia relacional", es decir, nuestra espiritualidad.

Así lo intuyó hace ya algunos años Jerome Berryman, el creador del método de enriquecimiento de la espiritualidad infantil Godly Play $^{12}$. El método presenta a los niños historias bíblicas a través de una narración oral acompañada por el uso de objetos tangibles y manipulables que representan figuras de las historias. Cuando el narrador se sienta en el suelo y presenta una narración en cualquiera de los cuatro géneros empleados en Godly Play, las historias sagradas, las parábolas, las acciones litúrgicas y el silencio contemplativo, no busca transferir un conocimiento, sino que los oyentes puedan "generar significado existencial". Y ese significado será tan personal como los límites del propio saber y existir del que escucha. Esta aproximación multisensorial permite el acceso a la lectura bíblica a niños y adultos, sea cual sea su etapa de desarrollo cognitivo.

Las historias sagradas, narrativas del Antiguo y del Nuevo Testamento, presentan al pueblo de Dios en busca de la presencia misteriosa de Dios. Los niños se unen a esta búsqueda, pues ya han co-

children's spirituality", International Journal of Children's Spirituality 9 (2004) 177-188, 180. La autora toma la interpretación de este comentario que hace P. Pitzele, Scripture Windows: Towards a Practice of Bibliodrama, Ben Yehuda Press, Los Ángeles 1998, 23-24 que lo emplea como base de su enfoque de la dramatización de la Biblia para invitar a las personas a entrar en el corazón de las historias bíblicas. En el ámbito rabínico el comentario se emplea para referirse a la Torá escrita y a la Torá oral.

12 Para una iniciación al método, ver J. Berryman, Godly Play. Método para enriquecer la espiritualidad infantil (Guía completa. Vol. 1), San Pablo, Madrid 2019. 
menzado a experimentar la presencia de Dios en sus vidas. Después de contar la historia, el narrador comienza una serie de "preguntas". El narrador reflexiona y se une con los niños a ese viaje que ha comenzado hace tantos años.

Las parábolas nos ayudan a contemplar la vida desde la nueva óptica del Reino. Jesús de Nazaret al contar las parábolas invitaba a sus oyentes a entrar en el juego, a romper los parámetros culturales que aprisionan la novedad del misterio de Dios. Por eso las parábolas no tienen una interpretación única, como tampoco son correctas o incorrectas las respuestas que dan los niños ante ellas. Al escuchar las parábolas, el niño descubre que el mismo Jesús entra en ese juego y participa con él.

El tercer tipo de lecciones que se emplean en Godly Play son las acciones litúrgicas. La liturgia une la narración pasada con la actualización de ese misterio en el hoy de la comunidad eclesial. El lenguaje verbal se queda corto para expresar tal misterio, por eso necesitamos de gestos y símbolos, colores y objetos litúrgicos que nos ayudan a hacer esta síntesis.

Y, por último, aunque está presente en todos los géneros anteriores, en Godly Play utilizamos el silencio, esos espacios en blanco que permiten que las palabras se oigan. Lo mismo que una hoguera necesita espacio entre sus troncos para el que fuego arda, nosotros necesitamos espacios de silencio para que esa palabra que viene de fuera y de dentro de nosotros, encuentre acogida y cree significado.

Veamos a continuación de qué manera las narrativas bíblicas y su modo de empleo en Godly Play contribuyen a nutrir la espiritualidad infantil, cultivando aquellos ámbitos privilegiados donde acontece la experiencia espiritual.

\subsection{La creación de espacios}

El espacio físico en Godly Play es una característica muy notable. A través del umbral, se entra a un nuevo espacio. Una parte de ese espacio está ya construido, las estanterías que rodean la sala, pero otra se va construyendo a medida de los niños se sientan en el círculo. Cuando nos 
sentamos en círculo, percibimos que somos importantes, que nosotros construimos el espacio en el que vamos a escuchar la historia. Y que el otro es importante, pues también construye el círculo. Pero no solo. El otro es "imprescindible".

El espacio exterior que rodea al círculo de niños nos envuelve con las historias sagradas, parábolas y acciones litúrgicas. Dispuestas alrededor de la sala, las historias de la Biblia nos abrazan, están a nuestra disposición y uno siente que "habita en la Biblia". Los objetos materiales que representan cada historia aguardan a ser "activados", como las letras que llenan las páginas del libro esperan que el lector les devuelva la vida. Cuando el narrador coloca la historia en medio del círculo, todas las miradas se dirigen a los materiales de la historia, también la mirada del narrador. El foco está en la historia, en la que nos sumergimos por el oído y la vista. Dispuestos en círculo, abrazamos la historia que vamos a escuchar y la historia nos abraza. Los que estamos en el círculo no solo escuchamos la historia, la contemplamos.

La narración crea círculo, pero no solo físico, también emocional. La fuerza de la historia escuchada nos envuelve en una atmósfera de experiencias compartidas. No en vano, las narraciones bíblicas, leídas en las casas o en las sinagogas, formaron y mantuvieron al pueblo de Israel a lo largo de los siglos. El relato crea pueblo, comunidad. Al escucharlo juntos, percibimos que contiene un sinfín de experiencias superiores a todo lo que un solo individuo pueda vivir y conocer en el curso de su vida $^{13}$. Basta escuchar, por ejemplo, la historia novelada de José: además de transmitir valores y experiencias, algunas escenas te hacen llorar de emoción contenida. La Biblia no está escrita para sacar ideas, ni mucho menos dogmas, está para acompañar experiencias, las que uno puede tener en la vida o las que le pueden llegar sin pretenderlo.

\subsection{La atención a los procesos}

Desde que se conocen y aplican los modernos métodos críticos de investigación bíblica, sabemos que las narraciones no sólo reflejan las experiencias de una comunidad en un tiempo concreto, sino el

13 G. Theissen, Motivare alla Bibbia. Per una didattica aperta della Bibbia, Paideia, Brescia 2005, 57. 
largo proceso por el que la tradición fue elaborando, ampliando, y anexionando otras experiencias. Para el historiador que se pregunta por la facticidad de los hechos, esto supone una molestia continua. Pero observando con detenimiento la complicada historia del proceso narrativo podemos concluir que nunca está terminada, ni siquiera después de haber quedado fijada con tinta en el papel. Así, por ejemplo, en un nivel narrativo, el relato de la salida de Abrahán de Ur, nos sirve casi mil años después para animar al pueblo exiliado en Babilonia a vivir la experiencia de volver a Jerusalén, pues también Dios está allí. O la misma experiencia del exilio es iluminada con el relato de la esclavitud en Egipto, para alentar a la esperanza de una liberación cercana.

La Biblia se detiene en los procesos porque Dios opera en el tiempo. Largo fue el proceso de Abrahán y Sara hasta que vieron cumplida la promesa, y largos se debieron hacer esos tres días en silencio en los que Abrahán se dirigió al monte Moria con su hijo Isaac. Largos los años de esclavitud en Egipto y los años vagando en el desierto tras la salida de Egipto. Es precisamente en los procesos largos donde se va operando la transformación en las personas y en el pueblo de Israel. El propio Jesús, "después de ser bautizado, cruzó el río Jordán y entró en el desierto. Estuvo allí durante cuarenta días y cuarenta noches para aprender más sobre quién era y cuál sería su trabajo"14. Saulo, todavía después de tener la experiencia de conversión, necesitó tiempo y se fue al desierto de Arabia, porque "estaba confundido y necesitaba entender lo que Dios quería que hiciera" Como leemos en la "parábola del pozo profundo", el viajero descubrió cómo sacar agua del pozo porque "se tomó su tiempo para estar realmente allí” ${ }^{16}$. La Biblia nos enseña a tener paciencia, a cuidar más el proceso que el producto.

Cuando en Godly Play contamos historias no nos precipitamos a sacar conclusiones o enseñanzas. Esto es muy propio de los adultos que se sitúan ante los niños desde una posición de maestro y discípulo. Parece que necesitamos dar una enseñanza, o hacer que el

14 Berryman, Godly Play, Vol. 4, 68.

15 Berryman, Godly Play, Vol. 4, 223.

16 Berryman, Godly Play, Vol. 3, 237. 
niño la descubra y la formule. Ni qué decir cuando el relato es una parábola. Estamos prontos a dar una explicación, la correcta, claro. Los ojos de los niños durante la narración de las historias y sus juegos y trabajos en el tiempo de respuesta nos muestran que ellos están realmente presentes y no necesitan demostrar nada con una respuesta "correcta" ni con un trabajo "perfecto".

\subsection{El espacio para la imaginación}

La narración de las historias bíblicas en Godly Play, así como todo lo que allí hacemos, sentimos y expresamos, tiene la función de dotar al niño del lenguaje que le permita afrontar los límites existenciales. A este fin, cobra especial protagonismo la imaginación. Y no solo para solucionar los problemas, sino para percibir la complejidad de la propia realidad. Los relatos bíblicos necesitan de la imaginación de los oyentes para rellenar los espacios libres que los autores han dejado, consciente o inconscientemente, en las narraciones. Pero no solo. La imaginación es capaz de generar, evocar y articular imágenes alternativas de la realidad, imágenes que se enfrentan a lo que el poder y el conocimiento hegemónico han declarado imposible. Esta inversión (subversión) de la realidad elimina el carácter absoluto y estable de lo que "el mundo" da por descontado, e invita a los oyentes del texto a reconsiderar lo que es dado o tomado por real ${ }^{17}$.

La imaginación tiene su espacio en el lenguaje religioso a través del símbolo, esa realidad sensible que evoca una realidad no sensible, transcendente (que no necesariamente divina) y que necesita de esa imagen alternativa de la que hablábamos. Literariamente se apoya en la metáfora o en sus formas derivadas, como puede ser la parábola. La metáfora permite expresar algo de la extrañeza del Dios de Israel y nos habla sobre la naturaleza juguetona y abierta del lenguaje y su imaginación "teológica".

La Biblia recurre a una amplia variedad de metáforas para referirse a Dios. Sin embargo, la metáfora no concuerda plenamente con

17 W. Brueggemann, Teología del Antiguo Testamento: un juicio a Yahvé. Testimonio, disputa, defensa, Sígueme, Salamanca 2007, 83-85. 
el esquivo Sujeto18. Éste "está" y "no está" a nuestra disposición al expresar el nombre. Así, cuando Israel afirma "Yahvé es mi pastor", el sustantivo pastor posibilita a Israel acceder de una imagen específica de Yahvé. Pero, al mismo tiempo, Yahvé no es un pastor. Esto no se debe a que pastor sea una metáfora pobre o inadecuada, sino a que el lenguaje sobre el elusivo Yahvé, en su naturaleza misma, permite esta reserva. Como sugiere McFague, la metáfora es un centinela frente a la idolatría en un testimonio que tiende al monoteísmo, pero a la vez media entre Dios y los seres humanos llenado el espacio entre su identificación y separación ${ }^{19}$.

¿Qué aporta esto a la experiencia religiosa? El símbolo apela a una realidad que no se percibe inmediatamente. Sin embargo, lo propio del símbolo es que tiene que producir la presencia inmediata de la realidad no inmediatamente percibida. El símbolo nunca puede ser explicado. En un determinado momento se puede hacer una elaboración racional. De eso se encargan los científicos de la literatura, cuando estudian la metáfora, por ejemplo. Pero en un texto religioso, el símbolo tiene que ser percibido en su propia inmediatez. Cuando se le racionaliza, no crea relación ${ }^{20}$. El poder expresar lo que el otro significa para mí, a través de una metáfora o un símbolo, es exactamente lo que me permite percibir el verdadero significado que el otro tiene para mí (Yahvé es mi pastor).

Por eso, lo propio del símbolo es conectar directamente con la experiencia de relación. En Godly Play encontramos los símbolos en las narraciones bíblicas -especialmente en las parábolas-, pero es en el género "acción litúrgica" donde se presentan a los niños diversos símbolos, pero conectados con la experiencia que los generó. Cuando vemos el pan en la eucaristía, conectamos con la experiencia de acogida que ofreció Sara a los tres viajeros, con la liberación que experimentó el pueblo de Israel en la noche que salió de Egipto, con la

18 S. McFague, Metaphorical theology. Models of God in Religious Language, Fortress Press, Philadelphia 1982.

19 F. Landy, "In the Wilderness of Speech: Problems of Metaphor in Hosea", Beauty and the Enigma. And Other Essays on the Hebrew Bible (JSOT SS 312), Bloomsbury, Sheffield 2001, 273-297, 280.

20 J. Garrido, Palabra de Dios y personalización, Frontera Hegian, Vitoria-Gasteiz 2003, 58-59. 
levadura que aportó la mujer en la parábola y que lo hizo fermentar todo y con la entrega de Jesús en la Última Cena. Cuando usamos el agua, como recordamos en el Bautismo: "Esta es el agua de la Creación, el agua peligrosa del Diluvio, el agua a través de la cual el Pueblo de Dios caminó hacia su libertad, el agua con la que Jesús fue bautizado, el agua con la que vosotros fuisteis o seréis bautizados" ${ }^{21}$, encontramos a través de ella a formar parte de esa salvación.

Los hombres y mujeres que vivieron esas experiencias están creando nuevas significaciones y necesitan nuevos vehículos de expresión. La Biblia ya ha creado esa experiencia, esos lenguajes, y nosotros, a través de las resonancias, encontramos en el símbolo no solo el vínculo con esa historia, sino el elemento que nos permite poner nombre a nuestra propia experiencia.

\subsection{El cuidado de las relaciones}

Como ya indicamos arriba, tanto Rebecca Nye como Tobin Hart señalan el carácter relacional de la espiritualidad. El encuentro humano es posible porque tiene su razón de ser en la dimensión subjetiva del hombre. El hombre posee como dimensión constitutiva su referencia personal a otras personas. Para el hombre, como ser abierto al mundo, los otros sujetos no son objetos de este mundo, sino con-sujetos con él. M. Buber es quizá el filósofo que mejor ha puesto de manifiesto las consecuencias de esta condición del hombre, cuando afirma "la relación con el ser humano es la auténtica alegoría de la relación con Dios"22, porque las líneas de las relaciones prolongadas se encuentran en el Tú eterno ${ }^{23}$. Y es que la relación con el absolutamente trascendente sólo puede ser vivida en términos de total trascendimiento, y éste se prepara, se realiza y se manifiesta

21 Berryman, Godly Play, Vol. 3, 115.

22 M. Buber, Yo y Tú, Nueva visión, Madrid 2005, 90.

23 Buber, Yo y Tú, 69. En esta misma línea afirma E. Lévinas, De Dios que viene a la Idea, Caparros, Madrid 1995, 17: "Pensamos que la idea-de-lo-Infinito-en-mí, o mi relación con Dios, me viene en la concreción de mi relación con el otro hombre, en la socialidad que es mi responsabilidad para con el prójimo: responsabilidad que no he contraído en ninguna 'experiencia' pero cuyo mandato, venido no se sabe de dónde, lo proclama el rostro del otro por su alteridad, por su extrañeza misma". 
en el descentramiento que requiere el reconocimiento de la alteridad del tú humano ${ }^{24}$.

Esto que nos enseña el pensamiento dialógico lo corrobora la psicología: la calidad de las relaciones está directamente relacionada con la calidad y desarrollo de la vida espiritual ${ }^{25}$. Es en la interacción con los otros donde surgen los sentimientos y actitudes de compasión y empatía. Una manera de fomentar esta relación entre adulto-niños y entre los niños es a través de la narración de una historia. Silke Rose West y Joseph Sarosy, autores de How to Tell Stories to Children, un libro dirigido especialmente a padres, afirman que cuando un niño pide que le cuentes una historia, lo que en el fondo está pidiendo es que le prestes atención ${ }^{26}$.

Cuando esta historia es una narración bíblica lo que hacemos es retomar el verdadero sentido de la historia: crear relación. En efecto, las historias de la Biblia nacieron como testimonios de un tejido de relaciones entre Dios y la humanidad, pero también entre los seres humanos. Siempre que leemos una historia de la Biblia nos asomamos a esa relación y, por su lectura, entramos en ella, formamos parte de esa relación. Cuando en la lectura de las historias sagradas se oye la pregunta: “¿Dónde estás tú en esta historia?" sentimos cómo la historia nos abraza y nos invita a entrar en ella. Ciertamente, cuando contamos una historia en la sala de Godly Play todos experimentamos una experiencia de comunión entre nosotros, con el pueblo de Dios y con Dios mismo. Al modo de nuestros antepasados que alrededor del fuego se sentaban a escuchar historias y percibir la presencia de Dios, los niños reciben la historia y entran en

24 Después de afirmar que el mundo de la relación se establece en tres esferas (la vida de la naturaleza, la vida de los hombres y la vida de las esencias espirituales), M. Buber se pregunta si nos es lícito integrar al inefable en el mundo de la palabra fundamental, en la relación, y responde: "En todas las esferas, gracias a todo lo que se nos hace presente, rozamos con la mirada la orla del Tú eterno; sentimos emanar un soplo que viene de él; en cada Tú invocamos el Tú eterno, según el modo propio de cada una de estas esferas". Buber, Yo y Tú, 14.

25 A. Berástegui Pedro-Viejo, "Reconocer la espiritualidad del niño", Sal Terrae 107 (2019) 295-307, 301.

26 S. R. West - J. Sarosy, How to Tell Stories to Children, HMH Books, Boston 2021. Muy interesante su web con diversos recursos: https://howtotellstoriestochildren.com/ 
ese círculo ancestral. Pero no solo. Al compartir el lenguaje común de las historias leídas durante tantos siglos y en tantos lugares del mundo, la narración crea comunión con los lectores-oyentes de todo el mundo, crea conciencia de Pueblo de Dios, comunidad, Iglesia Universal.

El tiempo de respuesta es el lugar privilegiado para las relaciones de crecimiento entre los oyentes. En Godly Play se cuida mucho este momento. Con sumo cuidado y casi de manera imperceptible, el narrador va dando paso a las intervenciones de los niños. Todas las respuestas son válidas, todas las reacciones son acogidas y respetadas, conscientes de que también en la Biblia encontramos esa diversidad. Las respuestas de unos enriquecen a otros niños, pero también al adulto. Cuando los adultos recibimos a los niños en el círculo, según la palabra de Jesús, le recibimos a Él (Mt 18,5; Mc 9,37; Lc 9,46-48) y su modo de estar y acoger la Palabra nos hace ser como niños (Mt 19,14;18,3; Mc 10,14-15; Lc 18,17) ${ }^{27}$.

\subsection{El necesario cuestionamiento}

El salmo 62 formula un principio hermenéutico que no debemos olvidar: "Dios ha dicho una cosa, y he escuchado dos" (Sal 62,12). En efecto, la palabra de Dios se bifurca sin cesar, crea nuevos significados, no solo cuando el autor emplea las metáforas, sino cuando el oyente la acoge con el necesario cuestionamiento, con la apertura a la posibilidad de que la propia palabra "viva y eficaz" genere nuevos significados.

Estos significados se generan en las sesiones de Godly Play tras la presentación de la lección, cuando tiene lugar la reflexión grupal o "wondering". Es el momento en que el narrador invita a los niños a preguntarse y admirarse por lo que acaban de escuchar y por los significados que la narración provoca en cada uno. No lo hace como pregunta directa a los niños, sino que honestamente él también entra en la reflexión: "Me pregunto... que podría ser esto en realidad". La reflexión es ligeramente distinta según sean historias sagradas, parábolas o acciones litúrgicas. Lo que buscamos en Godly Play es que el niño genere significado existencial para su vida.

27 Berryman, Godly Play, Vol. 1, 152. 
Las narraciones de las historias sagradas son el "escenario" donde tiene lugar el encuentro del pueblo de Dios con su Creador. En ellas, las preguntas del "wondering" van haciendo entrar al niño en la presencia misteriosa de Dios. La primera pregunta, "Me pregunto qué parte de la historia os ha gustado más”, es una invitación a conectar con los deseos de los niños, con aquello que les importa, que les sorprende. La segunda, "Me pregunto qué parte de la historia es la más importante", invita a dar el paso del "sentir" al "pensar", a profundizar en lo que ha sucedido en la narración. La tercera pregunta apela directamente a la vida del niño: "Me pregunto dónde estás tú en esta historia" o "Me pregunto qué parte trata sobre ti". Es la invitación a formar parte de esta gran historia, en la que todos tenemos cabida. La última pregunta, "Me pregunto si hay alguna parte de la historia que podríamos quitar y, aun así, tener toda la historia necesaria”, muchas veces crear cierta confusión en los adultos, sin embargo, es una manera de repasar la historia y darse cuenta de que tiene los elementos necesarios. Pero sirve también para localizar los posibles conflictos que la historia haya podido crear en el oyente. En muchos relatos hay cosas que nos gustaría quitar, como por ejemplo la muerte de los primogénitos. Como el objetivo de la narración no es que "aprendan" o "conozcan" historia sagrada, sino que vivan su experiencia de relación con Dios, es bueno que aflore el conflicto. Nosotros también entramos en el misterio del conflicto, porque no tenemos una respuesta como se esperaría de nosotros en un aula. Cuando leemos la Biblia observamos que, como en toda relación, hay conflicto. Y el conflicto no puede ser evitado, ni racionalizado, sino que se debe abordar desde un proceso de relación. Los conflictos nos acompañarán siempre en la lectura de la Biblia, pero también en nuestro proceso de fe y, si no los esquivamos con simplificaciones ingenuas o racionalizaciones vanas, nos ayudarán a transformar y madurar nuestra relación con Dios.

En las lecciones de las parábolas el cuestionamiento forma parte del propio relato. Las parábolas no son explicaciones, son invitaciones a dejarse cuestionar al confrontar nuestras lógicas humanas y culturales con las del Reino de Dios. Por eso Jesús suele terminar con la invitación. "el que tenga oídos para oír, que oiga”. En Godly Play, las preguntas de las parábolas son variadas, aunque tienen algo en 
común: buscan hacer entrar en el necesario "extrañamiento" que provoca la palabra de Jesús al acogerla con nuestras categorías. El niño prolongará después con el juego físico el juego semántico con el que ha ido entrando en la parábola. Y el juego será la puerta para "entrar en una relación con el Creador de las Parábolas"28.

En ese clima de preguntas, cabe que el niño se cuestione aspectos de su realidad, pero también del propio relato bíblico. No estará el narrador pronto a dar una respuesta "correcta", "aprendida", "ingenua”. Muchas veces lo mejor que puede hacer es responder: "yo también me lo pregunto".

\subsection{El misterio del asombro}

Una actitud tan propia de los niños como es el asombro resulta ser una puerta privilegiada no solo para la percepción del mundo que nos rodea, sino también para el encuentro con Dios. En efecto, el asombro y el temor reverencial nos abren a $\operatorname{Dios}^{29}$. ¿De qué manera las historias que leemos en la Biblia puede constituir para nosotros una experiencia radical de encuentro con Dios?

Recuerda Emil Ludwig Fackenheim que el pueblo judío fue el primero en afirmar el Dios de la historia ${ }^{30}$. En su obrita "La presencia de Dios en la historia”, explica cómo es en el judaísmo la estructura de la experiencia de ese Dios que actúa en la historia. Comienza señalando que una tradición judía considera el capítulo 1 de Ezequiel como el capítulo más profundo de la Biblia. Inicia así: "Los cielos se abrieron y vi visiones de Dios" (Ez 1,1). Sin embargo, la misma tradición, aunque parece contradecirse, afirma que lo que Ezequiel vio una vez en el cielo fue mucho menos de lo que todo Israel vio una vez en la tierra. Él y los profetas se vieron obligados a preguntarse: “quién es el rey?”. Pero en contraste con esto el pueblo de Dios en el Mar Rojo no necesitó preguntarse: "Tan pronto como lo vieron, lo reconocieron, y todos

28 Berryman, Godly Play, Vol. 1, 56.

29 A. J. Heschel, Dios en busca del hombre: una filosofía de la religión, Ed. Seminario, Buenos Aires 1984, 74-75.

30 E. L. Fackenheim, La presencia de Dios en la historia. Afirmaciones judias y reflexiones filosóficas, Sígueme, Salamanca 2002, 30. 
abrieron la boca para decir: 'Éste es mi Dios, yo lo glorificaré”" (Ex 15,2). Hasta la más humilde sirvienta en el Mar Rojo vio lo que jamás habían visto Isaías, Ezequiel y todos lo demás profetas. Fackenheim afirma que la experiencia individual de Ezequiel no constituye una experiencia radical (en el judaísmo), aunque podrá ser normativa para individuos aislados. Sin embargo, en el Mar Rojo, todo el pueblo vio, y lo que ocurrió ante sus ojos no fue una apertura de los cielos, sino una transformación de la tierra, acontecimiento histórico que afecta a las generaciones futuras. Cuando en la Haggadá de Pascua se rememora el Éxodo y la salvación en el Mar Rojo -y todos los actos históricos que recordamos en la Biblia- no se evocan sucesos pertenecientes a un pasado irrecuperable, sino que volvemos a interpretar estos sucesos como una realidad presente: solo así se cerciora de que el Dios salvador del pasado todavía salva.

Para explicar cómo entender una presencia divina que se manifiesta en y a través de un acontecimiento histórico, no en los cielos, Fackenheim recurre a un texto de Martin Buber en su libro Moisés donde escribe:

"lo decisivo desde el punto de vista de la historia interna de la humanidad [...] es que los hijos de Israel entendieron esto como un acto de su Dios, como un 'milagro'; lo cual no significa que lo interpretaran como milagro, sino que lo experimentaron como tal, que como tal lo percibieron..." (...) "El verdadero milagro consiste en que en la experiencia asombrosa de un suceso el sistema actual de causa y efecto se vuelve, por así decir, transparente y permite una ojeada en la esfera en la cual opera el poder único, sin verse limitado por ningún otro poder" ${ }_{31}$.

Los presentes en el Mar Rojo no infieren a su Dios a partir de un suceso histórico-natural, en un intento de explicar ese suceso. Un dios de esta clase no sería "creador del mundo" o "poder único", sino solo un "espíritu mágico". No sería "reconocido inmediatamente", sino que a lo sumo sería una hipótesis probable. Y no estaría presente, sino necesariamente ausente. Y el asombro se vería disipado por la explicación. El "poder único" está inmediatamente presente en el Mar Rojo, en y a través del suceso histórico-natural para asombro ilimitado de los testigos. Estos son los tres elementos de la experiencia radical y que solo son

31 M. Buber, Moses, Humanity Books, New York 1958, 57-58, y más extenso, 57-77. 
inteligibles cuando se ponen en relación: a) a no ser por la presencia inmediata del Poder único, el suceso no sería un milagro, sino un incidente extraño carente de explicación y el asombro solo sería curiosidad y se desvanecería cuando se diera la explicación; b) a no ser por el asombro ilimitado, el Poder único no estaría presente, o al menos no se sabría que estaba allí; y el milagro sería un mero incidente en espera de una explicación; c) a no ser por el suceso histórico-natural, el Poder único, si llegara a hacerse presente, o estaría presente en los cielos, más allá de la historia, o de lo contrario disolvería toda particularidad histórica por su presencia en ella; y el asombro ilimitado resultaría asimismo históricamente vacío.

Estos tres elementos de la experiencia radical que Fackenheim identifica en las vivencias del pueblo de Israel los encontramos también en la actividad de Jesús. Las acciones de Jesús, entre ellas las que llamamos "milagros", eran acogidas por las gentes con una actitud de asombro. El NT emplea el verbo thaumázō "sorprender", "maravillarse" unas 42 veces y traduce la impresión recibida por los hombres ante la acción salvífica y el poder prodigioso de Jesús, como por ejemplo, en la curación del endemoniado de Gerasa (Mc 5,20), en la maldición de la higuera (Mt 21,20) o en la curación del endemoniado mudo (Mt 9,33; Lc 11,14). Pero donde se percibe la cercanía entre la sorpresa y el temor reverencial es en el relato de la tempestad calmada: Mateo habla de admiración $(8,27)$, Marcos de miedo atroz $(4,41)$, mientras que Lucas une ambos conceptos: "Y despavoridos se maravillaron, diciéndose unos a otros: ¿Quién, pues, será este que manda a los vientos y al agua, y le obedecen?" (Lc 8,25) ${ }^{32}$.

¿En qué relación estamos nosotros con las criadas del Mar Rojo o con las gentes que contemplaron a Jesús de Nazaret? Cuando en Godly Play echamos mano de una historia y la llevamos al círculo de niños relatamos un suceso histórico-natural que se nos ha transmitido como actuar de Dios pero requiere del asombro. Si ahogamos el asombro con una explicación racional truncamos la experiencia radical de encuentro con el Misterio. El inocente "me pregunto" (I wonder) de nuestro Godly Play propicia que se active este círculo

32 W. Mundle, "Milagro", en L. Coenen - E. Beyreuther - H- Bietenhard, Diccionario teológico del Nuevo Testamento. Vol. III, Sígueme, Salamanca 1983, 85-89. 
virtuoso por el cual lo que ahí se cuenta que experimentaron, yo lo puedo experimentar en el aquí y ahora. El Dios que se hizo presente allí, se me hace presente aquí.

\subsection{La sabiduría de contemplar lo invisible}

Cuando hablamos de que los niños tienen una sabiduría especial para contemplar lo invisible, nos referimos a su capacidad para acceder a la profundidad de las realidades, para llegar a los niveles más profundos de conocimiento a los que se accede por la contemplación. El acceso a esta fuente de sentido es una habilidad importante que encontramos en muchas tradiciones religiosas y filosóficas y, por supuesto, en la religión de Israel.

Algunos personajes de la Biblia, como los profetas, encontraron esa fuente en Dios. Ciertamente ellos hablaban desde Dios, para la realidad histórica concreta. Pero si los profetas conectaron con Dios para hablar a la historia, los sabios de Israel fueron contemplativos de la realidad cotidiana. Desde el centro del ser humano se descubren interrogantes y malestares existenciales. Ellos nos hablan de la complejidad de la vida humana con sus grandes enigmas: el sentido de la vida, el sufrimiento, la posibilidad de felicidad, el papel de Dios en la realización del hombre. Los libros sapienciales del Antiguo Testamento recogen el intento de los sabios de Israel de abordar la vida humana en toda su profundidad. Por eso, los sabios son finos observadores de la realidad, contemplativos de todo lo humano ${ }^{33}$.

Pero en la propia Biblia encontramos un riesgo que podemos correr hoy también: la tentación de simplificar, de no entrar en la complejidad de la vida. Hay personas que no son capaces de manejar la incertidumbre, la duda, el silencio apofático. Entonces su mirada a la realidad se alía con la simplificación, la respuesta fácil. En la conocida como "sabiduría tradicional" la visión de la realidad es simple e ingenua y no pone signos de interrogación o de duda allí donde no llega la comprensión de la razón humana. El hombre que mira así la realidad cree tener un conocimiento de ella firme, seguro, sin fisuras, comparable a una piedra

33 J. L. Elorza, Drama y esperanza. III. El ser humano interrogado por la realidad, Verbo Divino, Estella 2005. 
de granito. Pero, en la historia de Israel, a medida que el pueblo sufre pruebas surgen preguntas y dudas que ponen a prueba una concepción religiosa que hasta entonces se había mantenido casi sin fisuras. Aparece entonces el espíritu crítico, la mirada del sabio que no esquiva la complejidad de la vida. Más que contemplar lo invisible, el sabio se atreve a poner nombre a lo que nadie quiere mirar.

Cuando a los niños no les ocultados la complejidad de vida, en muchos casos nos sorprenden por su capacidad de acceder a otros niveles de sentido. Cuando en las parábolas, por ejemplo, preguntamos "qué podría ser esto", invitamos a mirar más allá de la realidad de lo que el ojo puede ver. Los niños son capaces de ver otras dimensiones. Cuando pregunto a grupos de profesoras o madres alguna experiencia que hayan vivido u observado a este respecto, en varias ocasiones me han comunicado una experiencia semejante: la capacidad de los niños para verbalizar y sentir que la pérdida de seres queridos no es más que el paso a un "lugar" donde se van a encontrar con otros que ya han dado ese paso y donde nos aguardan. Recuerdo cómo una profesora se quedaba admirada de la naturalidad con la que hablaban los niños de sus experiencias con la pérdida de sus familiares o de sus mascotas cuando ningún adulto intervenía en sus conversaciones.

Los niños tienen acceso a visiones que quizás para los adultos están ya cegadas. Nosotros podemos escucharles y, todo lo más, ayudarles a dar nombre. Es el caso de la visión del niño Samuel en el templo de Siló. Así lo contamos en Godly Play:

"Una noche cuando Samuel dormía sobre su alfombra en la tienda, Dios le llamó: ‘Samuel, Samuel!' Samuel pensó que debía de ser Elí llamándole, así que fue hacia él. Pero Elí no le había llamado y le mandó a acostarse de nuevo. Esto pasó dos veces más, hasta que Elí se dio cuenta de que era Dios quien llamaba a Samuel. Le mandó volver a acostarse y le dijo: "Si oyes otra vez la voz, contesta: Habla, Señor, porque tu siervo te escucha"'s4.

Elí no oyó a Dios, sin embargo, creó el espacio en el templo para que el niño pudiera oír la voz de Dios y después, le acompañó para dar nombre a esa experiencia.

34 Berryman, The Complete Guide to Godly Play. (Vol. 6, Revised and Expanded), New York 2021, 107. 
Esa fuente de sabiduría no solo está en aquellos que poseen conocimientos sobre Dios o sus leyes, también en el propio interior del niño. De Jesús niño, nos cuenta Lucas que se perdió en el templo y "al cabo de tres días lo encontraron, sentado entre los maestros de la ley, escuchándolos y haciéndoles preguntas. Y todos los que lo oían se admiraban de su inteligencia y de sus respuestas" (Lc 2,46-47) ${ }^{35}$.

\section{Conclusión}

Las narraciones bíblicas, que fueron escritas para dejar testimonio de la multiforme variedad de aspectos de la relación de los hombres con Dios, se nos presentan como una óptima mediación para el cultivo de la espiritualidad de la infantil. Narradas con ese mismo espíritu, en el círculo de niños encuentran la tierra fértil capaz de acoger la palabra. Dada la capacidad natural de los niños para lo espiritual, las narrativas bíblicas conectan con sus situaciones vitales al verse formando parte del mismo universo de experiencias. Los relatos bíblicos, así como los gestos y símbolos, crean relación con el protagonista divino último de los mismos. Los niños encuentran en ellas el lenguaje que le permite poder hablar de lo que sienten, de sus ilusiones, de sus miedos, de sus búsquedas.

La Biblia sigue siendo necesaria para la educación de la fe, pero lo es también para la espiritualidad de la infancia. Cuando leemos la Biblia con ellos, los niños nos enseñan a poner atención a ciertos detalles, como el espacio físico o emocional; a prestar más atención a los procesos que a los productos; a no precipitarnos a encontrar respuestas fáciles, sino aceptar que emerjan preguntas; a dar cabida a la imaginación y al asombro, para explorar nuevos significados que nos posibiliten contemplar lo invisible. El círculo de niños se convierte así en lugar hermenéutico.

35 Así lo narramos en Godly Play, en la lección de los "Rostros de la Pascua": "Estaba hablando con los rabinos y los sacerdotes del templo. Cuando él hablaba, ellos escuchaban, porque él sabía tantas cosas. Cuando ellos hablaban, él escuchaba, porque quería aprender más". Berryman, Godly Play, Vol. 4, 60. 